\title{
Introduction to the Organisation
}

\section{The Clan Campbell Education Association, Inc.}

This volume is dedicated to a true leader and friend of the Clan Campbell, Ian Campbell, MacCailein Mor and 12th Duke of Argyll. He was instrumental in the formation of the Clan Campbell Society (USA) and always took a great interest in their activities. Argyll took his position as Clan Chief most seriously, from providing arms for the Clan Societies to establishing a position on appropriate tartans and clan septs. When visiting our meetings, he insisted on putting the clan before other activities and, from this accessibility, many members came to know him for his warmth and humour. He was also a great supporter of the CCEA and, especially, this History of the Clan Campbell. We will all miss him.

The Clan Campbell Education Association was founded in 1992 by members of the Board of Directors of the Clan Campbell Society (North America). The Association exists to educate its members and the public about the Scots and Scotland in general and about the Clan Campbell in particular. It promotes the study, health, and perpetuation of Scottish Culture, including music, dance, art, athletics, language, and cuisine and it supports and conducts charitable and educational activities that advance this purpose. The Association also encourages the study of Scottish history and culture by financing scholarships, grants, loans, and the award of incentives at Highland Games and competitions. Its present officers are Joseph McDowell Campbell, Jr - President, John Wendell Campbell - Vice President, Ruby Campbell, $\mathrm{PhD}$ - Secretary, and Douglas D. Caddell - Treasurer.

In 1997 the Association commissioned Alastair Campbell of Airds to write a three-volume history of the Clan Campbell and thus to fill a large gap in Clan - indeed Scottish - historiography. Funding for the project came from generous donations of Campbells worldwide as well as from other clans, including the Clan Donald. The project was built on earlier research funded by the now inactive Jacob More Society, founded by the late Hugh Purfield Moore. 
Listed below, for the recognition they so richly deserve, are the major contributors who have made this history a reality. They are worthy of our gratitude for making possible a legacy that will last forever.

Joseph McDowell Campbell, Jr President, CCEA

\section{List of GGEA Patrons}

Verda McClung Anderson

Dr \& Mrs. Stephen S. Bell

David \& Mary Bernhardt

William H. Burns, Jr

Charles T. \& Nancy J. D. Campbell

Clyde H. 'Bill' \& Paula Campbell

Colin D. \& Sherie Campbell

David R. \& Mary E. 'Betsy' Campbell

Dewey G. \& Rosemary H. Campbell

In Memory of parents Donald \& Betty Campbell - Alan K.

\& Isabelle Campbell DerKazarian

Mr. \& Mrs. Donald Draper Campbell

Frederick H. Campbell

Dr \& Mrs. Frederick W. Campbell

In Memory of Henry Alexander Campbell, Florida (1901-1977)

Mr. \& Mrs. Carl A. Guilford, Jr

Hyle \& Joanne Campbell

In Memory of J. Lyle Campbell, Editor Emeritus of the

CCS (NA) Journal - V. Wilson \& Ruth Campbell

J. Richard \& Barbara J. Campbell

James R. Campbell

Mr. \& Mrs. Jerry Campbell

John A. 'Scotty' Campbell

Lt. Col. John W. \& Mrs. Marilyn A. Campbell, USMC (Ret.)

Col. \& Mrs. Joseph McDowell Campbell, USAF (Ret.)

Kenneth B. \& Ruby G. Campbell 